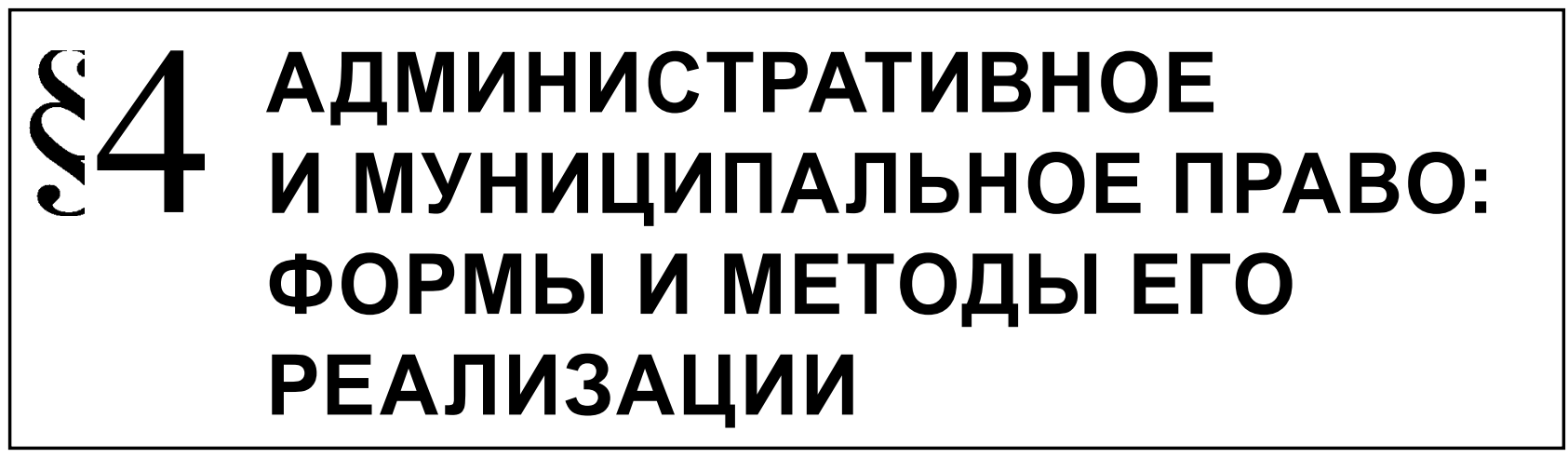

Фролов В.А.

\title{
ЮРИДИЧЕСКИЕ КОНСТРУКЦИИ РЕАЛИЗАЦИИ ЗАПРЕТОВ И ОГРАНИЧЕНИЙ ПРИ ВВОЗЕ ИЛИ ВЫВОЗЕ ЧЕРЕЗ ТАМОЖЕННУЮ ГРАНИЦУ ТАМОЖЕННОГО СОЮЗА
}

\begin{abstract}
Аннотация: Многообразие форм общественных отношений, которое было порождено переходом России на свободный экономический путь развития, опосредовало необходимость изучения их конструкций, выявление системности, познание элементов, приемов и средств, с помощью которых они регулируются государством. В настоящей статье автор рассматривает юридические конструкции реализации отношений в сфере установления не носящих экономический характер запретов и ограничений в таможенных правоотношениях, выделяет элементы этих отношений, предлагает для научной дискуссии определение юридической конструкции реализации отношений в срере установления не носящих экономический характер запретов и ограничений в таможенных правоотношениях, рассматривает практические примеры.Опираясь на выведенную юридическую конструкцию установления запретов и ограничений в таможенных правоотношениях и ее элементы автором предпринята попытка составить модель общественных отношений, которые возникают в срере таможенных правоотношений при пересечении товаров, транспортных средств через таможенную граничу ТС. Методологическую основу составляют: диалектический метод познания, основы философии и теории права, которые позволили раскрыть особенности, сущность, внутренние связи и обнаружить противоречия между двумя правовыми категориями: «запреты» и "ограничения», их целостность и системность и, которые обеспечили предпосылки для выявления проблем и составления собственного понимания и представления об изучаемых категориях. В статье сделан вывод о том, что юридическая конструкция установления не носящих экономического характера запретов и ограничений в таможенных правоотношениях есть средство, с помощью которого осуществляется моделирование общественных отношений во внешнеэкономической деятельности. Установлено, что основу юридической конструкции реализации правовых запретов и ограничений в таможенной сфере составляют три основных элемента: международные, межнациональные и национальные нормы-принципы; правовые нормы, устанавливающие права и обязанности участников внешнеэкономической деятельности; правовые приемы и средства (механизм) государственного принуждения, обеспечивающие должное поведение участников ВэД, а также нормы, закрепляющие ответственность за нарушение установленных правил.

Ключевые слова: запреты, ограничения, юридические конструкции, таможенные правоотношения, внешнеэкономическая деятельность, международные нормы, принципы, правовые нормы, средства, Таможеннный Союз.
\end{abstract}

$\mathrm{B}$ современных условиях развития общества, является практически необходимым и теоретически оправданным исследование различных групп общественных отношений, правовых конструкций регулирования этих отношений, выявление определенных систем и познание их элементов, установление взаимосвязей, детализация соотношений и взаимозависимостей. 
Конструкция (от лат. - constructio) - означает строение, устройство, взаимное расположение частей какого-либо предмета, прибора, сооружения и т.п., определяющееся его назначением ${ }^{1}$; конструкция - это состав и взаимное расположение частей какого-нибудь построения, механизма, а также само такое построение 2 .

К сожалению, теоретиками права не выработано четкого обоснования и понятия юридической конструкции. Каждый теоретик закладывает в ее содержание свое понимание, не всегда приводя доводы и обоснования. Так, А.Ф. Черданцев определяет юридическую конструкцию как некую форму отражения действительности и подчеркивает ее гносеологический характер, поскольку она служит методом познания права и урегулированных им общественных отношений ${ }^{3}$. Н.Н. Тарасов указывает на методологическое значение юридических конструкций ${ }^{4}$. Нередко юридические конструкции отождествляются с исследованием юридической техники ${ }^{5}$ и ее элементами ${ }^{6}$.

Нам представилась наиболее интересной позиция С.С. Алексеева, который под юридической конструкцией предложил понимать типовые схемы построения прав, обязанностей и ответственности, в которые облекается «юридический материал» ${ }^{7}$, поскольку именно эта позиция наиболее полно отражает рассматриваемую в исследовании тему.

В нашем понимании юридические конструкции реализации отношений в сфере установления не носящих экономический характер запретов и ограничений в таможенных правоотношениях суть правовые явления, имеющие определенное

1 Современный словарь иностранных слов. СПб, 1994. С. 303.

2 Ожегов С.И., Шведова Н.Ю. Толковый словарь русского языка. М., 2008. С. 291.

3 См.: Черданцев А.Ф. Логико-языковые феномены в праве, юридической науке и практике. Екатеринбург, 1993. С. 131 132.

4 См.: Тарасов Н.Н. Методологические проблемы современного правоведения: Дис. ... д.ю.н. Екатеринбург, 2002. С. $292-320$.

5 См. Алексеев С. С. Право. Азбука. Теория. Философия. Опыт комплексного исследования. - М.: Издательская группа НОРМА - ИНФРА-М, 1998; Иеринг Р. Юридическая техника / Пер. с нем. Ф.С. Шендорфа. СПб., 1905.

6 См.: Юридический словарь [Электронный ресурс]. URL: http: //dic.academic.ru/dic.nsf/lower.

7 См. Алексеев С. С. Там же. строение, структуру этих отношений. Юридическая конструкция установления запретов и ограничений в таможенных правоотношениях нами воспринимается как средство, с помощью которого осуществляется моделирование общественных отношений при пересечении товаров, транспортных средств, людей через таможенную границу ТС. Элементами этой конструкции выступают:

международные, межнациональные и национальные нормы-принципы, которые лежат в основе норм, устанавливающих запреты и ограничения для участников ВЭД, охраняющих суверенитет государств, обеспечивающих национальную безопасность, развитие предпринимательства, повышение уровня и благосостояния граждан;

права и обязанности участников внешнеэкономической деятельности, закрепленные в правовых актах международного уровня (в рамках документов стран-участников ТС, Совета ЕврАзЭС), конституциях соответствующих стран-участников TC, национальных нормативных правовых актах, устанавливающих нормы о запретах и ограничениях для участников ВЭД;

правовые приемы и средства (механизм) государственного принуждения, обеспечивающие должное поведение участников ВЭД, а также нормы, закрепляющие ответственность за нарушение установленных правил.

Юридические конструкции в таможенных правоотношениях следует признать важнейшим средством, обеспечивающим единство основополагающих принципов, нормативного массива и соответствие предписаний позитивного права природе таможенных отношений ввиду ряда их особенностей и специфике реализации.

Формирование юридических конструкций во внешнеэкономической деятельности является определенным показателем развития внешнеэкономических отношений, отражающих логику их построения. Юридические конструкции реализации запретов и ограничений в таможенных правоотношениях несут существенную социально-политическую, финансово-экономическую, идеологическую нагрузку, что определяет их тесную взаимосвязь с принципами правового регулирования внешнеэкономических отношений.

Д.В. Богданов пишет о том, что «развитие системы нормативно закрепленных юридических конструкций свидетельствует о высокой степени организации нормативного материала, и с указанной точки зрения они (конструкции) могут быть рассмотрены в рамках юридической 
техники» ${ }^{8}$. М.Ю. Челышев отмечает, что юридические конструкции видов правоотношений следует определять через призму инструментального подхода, поскольку юридические конструкции представляют собой конкретный способ закрепления в законодательстве разного рода правовых инструментов 9 .

Между тем следует отметить, что юридические конструкции реализации запретов и ограничений в таможенных правоотношениях в рамках ТС являются искусственно выведенными сооружениями и отражают внешнюю и внутреннюю социально-экономическую политику государств-участников ТС. Юридические конструкции реализации запретов и ограничений в таможенных правоотношениях в рамках ТС имеют внешнее строение, внутреннюю структуру и взаимосвязанные элементы, на которых основываются эти конструкции.

К разновидностям юридических конструкций реализации запретов и ограничений в таможенных правоотношениях в рамках ТС возможно отнести:

- юридические конструкции реализации запретов и ограничений таможенными органами Российской Федерации, а также таможенными органами стран-участников ТС;

- юридические конструкции реализации запретов и ограничений судебными органами Российской Федерации и иными участниками ТС;

- юридические конструкции реализации запретов и ограничений вне рамок ТС.

Приведенные разновидности конструкций реализации запретов и ограничений в таможенных правоотношениях призваны воздействовать на специфическую область фактической человеческой деятельности и являются наиболее адекватным и рациональным способом применения совокупности правовых инструментов, охватываемых соответствующей юридической сферой. Каждая из приведенных юридических конструкций представляет собой единую синтаксическую единицу. Кроме того, следует сделать акцент на имманентной системности, поскольку ее структурные элементы связаны внутренним содержанием. Элементы кон-

\footnotetext{
8 См. Богданов Д.В. К вопросу о юридических конструкциях в налоговом праве // Финансовое право. 2010. № 11.

9 Челышев М.Ю. О юридических конструкциях в проекте изменений и дополнений в Гражданский кодекс Российской Федерации // Сборник по итогам Всероссийской научнопрактической конференции «Изменения в Гражданском кодексе Российской Федерации: новеллы гражданского законодательства - 2012». М.: Изд-во «Юрист», 2012. С. 80 - 81.
}

струкции возникают не произвольно, а являются результатом определенного волеизъявления государств-участников ТС, участников внешнеэкономической деятельности с Россией, обязательно взаимосвязаны, имеют прикладное значение для функционирования данной системы.

С другой стороны, каждая вышеприведенная юридическая конструкция реализации запретов и ограничений таможенными органами представляет собой совокупность объективно необходимых упорядоченных и взаимосвязанных элементов, т.е. систему. При этом особенности внутренней структуры (содержания) каждой такой системы, состав ее элементов позволяют их отличать, выделить характерные признаки, функции и т.п. Все вышеприведенные юридические конструкции, с одной стороны, являются имманентными системами, состоящие из определенных элементов, - с другой сами логически организованы в стройную систему более высокого уровня, выступая ее элементами.

Отдельно следует отметить, что механизм реализации правовых запретов и ограничений в практике таможенных органов имеет свою специфику и отличен от общеправового механизма. При этом, в нем присутствуют идентичные элементы, например, принципы, правовые нормы, правоотношения.

Рассмотрим пример разновидности юридической конструкции реализации не носящих экономического характера запретов и ограничений таможенными органами Российской Федерации в части нарушения запрета на предоставление таможенному представителю недействительных документов при совершении таможенных операций (статья 16.7 КоАП РФ). В диспозиции статьи 16.7 КоАП РФ законодательно закреплен запрет, в силу которого представление декларантом или иным лицом таможенному представителю либо иному лицу документов для представления их в таможенный орган при совершении таможенных операций, повлекшее за собой заявление таможенному органу таможенным представителем либо иным лицом недостоверных сведений о товарах и (или) несоблюдение установленных международными договорами государств - членов ТС, решениями Комиссии ТС и нормативными правовыми актами Российской Федерации, изданными в соответствии с международными договорами государств - членов ТС, запретов и ограничений, влечет применение мер ответственности по законодательству об административных правонарушениях. Под недействительными документами 
понимаются поддельные документы, документы, полученные незаконным путем, документы, содержащие недостоверные сведения, документы, относящиеся к другим товарам и (или) транспортным средствам, и иные документы, не имеющие юридической силы ${ }^{10}$.

Опираясь на изложенную нами выше юридическую конструкцию установления запретов и ограничений в таможенных правоотношениях и ее элементы составим модель общественных отношений, которые возникают в случае предоставления декларантом или иным лицом таможенному представителю документов для представления их в таможенный орган при совершении таможенных операций при пересечении товаров, транспортных средств через таможенную границу ТС.

В международных, межнациональных и национальных правовых документах установлены принципы, которые лежат в основе норм, устанавливающих запреты и ограничения для участников ВЭД, охраняющих суверенитет государств, обеспечивающих национальную безопасность, развитие предпринимательства, повышение уровня и благосостояния граждан, а также свободное перемещение товаров, услуг и финансовых средств, поддержку конкуренции, свободу экономической деятельности (см., например, статья 8 Конституции РФ).

При осуществлении своих прав и свобод каждый человек должен подвергаться только таким ограничениям, какие установлены законом исключительно с целью обеспечения должного признания и уважения прав и свобод других и удовлетворения справедливых требований морали, общественного порядка и общего благосостояния в демократическом обществе, сказано в пункте 2 статьи 29 Всеобщей декларации прав человека ${ }^{11}$.

В силу закона участники внешнеэкономической деятельности имеют право, как самостоятельно участвовать в оформлении таможенных деклараций, так и обращаться к услугам таможенных представителей. Таможенный представитель - юридическое лицо государства - члена ТС, включенное в реестр таможенных представителей и отвечающее условиям, определенным статьей 13 ТК ТС. Право совершать от имени и по поручению декларанта или иных заинтересованных лиц таможенные операции в соответствии с таможенным законодательством ТС на территории госу-

\footnotetext{
10 См. Примечание к статье 16.1 КоАП РФ.

11 Принята Генеральной Ассамблеей ООН 10.12.1948//Российская газета, 1995. 05 апреля, - № 67.
}

дарства - члена ТС, таможенным органом которого он включен в реестр таможенных представителей, таможенный представитель пользуется в силу положений ТК ТС, международных договоров и иных актов стран-участников ТС, а также национального законодательства государства члена ТС.

Права и обязанности участников внешнеэкономической деятельности закрепляются в правовых актах международного уровня (в рамках документов стран-участников ТС, Совета ЕврАзЭС), национальных нормативных правовых актах. Например, в Гражданском кодексе Российской Федерации закреплены нормы о свободе предпринимательской деятельности, свободе договора, свободе выбора сторон и содержания договора и другие. Деятельность таможенных представителей - это предпринимательская деятельность юридических лиц, которая регулируется как гражданским, так и таможенным (в рамках национального) законодательством Российской Федерации. Для таможенных представителей характерным видом такой деятельности является выполнение работ и оказание услуг, поскольку процесс перемещения товаров через таможенную границу осложняется определенными условиями, требующим профессиональной помощи, а также навыков компетентных специалистов. Несмотря на наличие диспозитивных норм в гражданском законодательстве о взаимоотношениях участников ВЭД и таможенных представителей, имеется ряд императивных норм, которые применяются к таким лицам в соответствии с ТК ТС и ФЗ «О таможенном регулировании в РФ».

Правоотношения, которые связаны с перемещением людей, товаров, транспортных средств через таможенную границу ТС, регулируются в соответствии с таможенным законодательством ТС. Международные договоры и решения органов ТС действуют в РФ непосредственно, если не содержат в себе требований о необходимости издания национальных актов для применения содержащихся в них положений. При этом Правительство РФ вправе определять порядок применения актов TC, если это не противоречит наднациональным интересам.

Каждое государство заинтересовано в том, чтобы в обществе соблюдались, принятые и законно введенные правила и нормы. При этом ни одно государство не лишено деструктивных проявлений в обществе. В целях соблюдения запретов и ограничений всеми участниками правоотношений каждое государство вырабатывает 
некие правовые механизмы их реализации. Под правовым механизмом обычно понимают совокупность правовых приемов и способов, при помощи которых органами исполнительной власти осуществляется регулирующее воздействие на участников правоотношений. Так государство вырабатывает правовые приемы и средства принуждения, обеспечивающие должное поведение участников ВЭД, а также нормы, закрепляющие ответственность за нарушение установленных правил. Законами Российской Федерации установлена административная и уголовная ответственность за нарушения запретов и ограничений участниками ВЭД. Административная ответственность наступает за совершенное административное правонарушение физическими и юридическими лицами, соответственно уголовная - за общественно-опасное, виновное, противоправное действие (бездействие) физических лиц- участников ВЭД. Ответственность наступает в связи с наличием установленного юридического факта о нарушении запрета или ограничения.

Субъект правонарушения определен в диспозиции статьи 16.7 КоАП РФ. Это может быть гражданин, должностное лицо или юридическое лицо. В зависимости от стадии таможенной процедуры, когда таможенному органу заявляются письменно или сообщаются иным образом сведения о перемещаемых товарах и транспортных средствах, субъектом может выступать лицо, обладающее полномочиями в отношении товаров, перевозчик, декларант. Субъективная сторона правонарушения выражается виной в форме прямого умысла или неосторожности, при предоставлении недействительных документов или сведений таможенному представителю.

Дела об административных правонарушениях, предусмотренных статьей 16.7 КоАП, в соответствии со статьей 23.8 КоАП РФ, рассматривают должностные лица таможенных органов, а также судьи (ч. 2 ст. 23.1). Протоколы об административном правонарушении составляют должностные лица таможенных органов (ч. 1 ст. 28.3).

Таким образом, юридическая конструкция правила, закрепленного в статье 16.7 КоАП РФ основана на принципах, закрепленных в международных нормах, межнациональных (наднациональных) договорах стран-участников ТС, а также в национальном законодательстве стран-участников ТС; на закрепленных в национальных нормативных правовых актах правах и обязанностях, участников ВЭД; нормах об ответственности, за нарушение запрета на предоставление декларантом или иным лицом таможенному представителю либо иному лицу документов для представления их в таможенный орган при совершении таможенных операций, недостоверных сведений о товарах и (или) несоблюдение установленных международными договорами государств - членов Таможенного союза запретов и ограничений.

Нами сделан вывод о том, что юридическая конструкция установления не носящих экономического характера запретов и ограничений в таможенных правоотношениях есть средство, с помощью которого осуществляется моделирование общественных отношений во внешнеэкономической деятельности. Установлено, что основу юридической конструкции реализации правовых запретов и ограничений в таможенной сфере составляют три основных элемента:

- международные, межнациональные и национальные нормы-принципы;

- правовые нормы, устанавливающие права и обязанности участников внешнеэкономической деятельности;

- правовые приемы и средства (механизм) государственного принуждения, обеспечивающие должное поведение участников ВЭД, а также нормы, закрепляющие ответственность за нарушение установленных правил.

\section{Библиография:}

1. Таможенный кодекс Таможенного союза.

2. Всеобщая декларация прав человека/принята Генеральной Ассамблеей ООН 10.12.1948// Российская газета, 1998. 10 декабря.

3. Кодекс Российской Федерации об административных правонарушениях от 30 декабря 2001 г. № 195 -Ф3 «Собрание законодательства РФ», 07.01.2002, № 1 (ч. 1), ст. 1.

4. Федеральный закон от 27 ноября 2010 № 311-ФЗ «О таможенном регулировании в Российской Федерации»//С3 РФ, 2010. - № 48. - Ст. 6252.

5. Постановление Правительства РФ от 16.09.2013 № 809 (ред. от 02.11.2013) «0 Федеральной таможенной службе» (вместе с «Положением о Федеральной таможенной службе»)// СЗ РФ, 2013.-№ 38.-С. 4823.

6. Административный запрет как средство противодействия коррупции в системе государственной службы: учебное пособие. Авторы: Костенников М.В., Куракин А.В. Издательство: Юнити-Дана; Закон и право, 2012 г. $128 \mathrm{c.}$ 
7. Алексеев С. С. Право. Азбука. Теория. Философия. Опыт комплексного исследования.-М.: Издательская группа НОРМА - ИНФРА-М, 1998; Иеринг Р. Юридическая техника / Пер. с нем. Ф.С. Шендорфа. СПб., 1905.

8. Богданов Д.В. К вопросу о юридических конструкциях в налоговом праве // Финансовое право. 2010 . № 11.

9. Ожегов С.И., Шведова Н.Ю. Толковый словарь русского языка. М., 2008. С. 291.

10. Тарасов Н.Н. Методологические проблемы современного правоведения: Дис. ... Д.ю.н. Екатеринбург, 2002. С. 292320.

11. Челышев М.Ю. О юридических конструкциях в проекте изменений и дополнений в Гражданский кодекс Российской Федерации // Сборник по итогам Всероссийской научно-практической конференции «Изменения в Гражданском кодексе Российской Федерации: новеллы гражданского законодательства - 2012». М.: Изд-во «Юрист», 2012. C. 80-81.

12. Черданцев А.Ф. Логико-языковые феномены в праве, юридической науке и практике. Екатеринбург, 1993. С. 131132.

13. Чермянинов Д.В. Таможенное право/под ред. Д.Н. Бахраха. М.: Юрайт, 2013. - С. 20.

14. Юридический словарь [Электронный ресурc]. URL: http: //dic.academic.ru/dic.nsf/lower

\section{References (transliterated):}

1. Tamozhennyi kodeks Tamozhennogo soyuza.

2. Vseobshchaya deklaratsiya prav cheloveka/prinyata General'noi Assambleei OON 10.12.1948// Rossiiskaya gazeta, 1998. 10 dekabrya.

3. Kodeks Rossiiskoi Federatsii ob administrativnykh pravonarusheniyakh ot 30 dekabrya 2001 g. № 195 -FZ «Sobranie zakonodatel'stva RF», 07.01.2002, № 1 (ch. 1), st. 1.

4. Federal'nyi zakon ot 27 noyabrya 2010 № 311-FZ «0 tamozhennom regulirovanii v Rossiiskoi Federatsii»//SZ RF, 2010. - № 48. - St. 6252.

5. Postanovlenie Pravitel'stva RF ot 16.09.2013 № 809 (red. ot 02.11.2013) «0 Federal'noi tamozhennoi sluzhbe» (vmeste S «Polozheniem o Federal'noi tamozhennoi sluzhbe»)// SZ RF, 2013.-№ 38.-S. 4823.

6. Administrativnyi zapret kak sredstvo protivodeistviya korruptsii v sisteme gosudarstvennoi sluzhby: uchebnoe posobie. Avtory: Kostennikov M.V., Kurakin A.V. Izdatel'stvo: Yuniti-Dana; Zakon i pravo, 2012 g. 128 s.

7. Alekseev S. S. Pravo. Azbuka. Teoriya. Filosofiya. Opyt kompleksnogo issledovaniya.-M.: Izdatel'skaya gruppa NORMA INFRA-M, 1998; Iering R. Yuridicheskaya tekhnika / Per. s nem. F.S. Shendorfa. SPb., 1905.

8. Bogdanov D.V. K voprosu o yuridicheskikh konstruktsiyakh v nalogovom prave // Finansovoe pravo. 2010 . № 11.

9. Ozhegov S.I., Shvedova N.Yu. Tolkovyi slovar' russkogo yazyka. M., 2008. S. 291.

10. Tarasov N.N. Metodologicheskie problemy sovremennogo pravovedeniya: Dis. ... d.yu.n. Ekaterinburg, 2002. S. 292-320.

11. Chelyshev M.Yu. O yuridicheskikh konstruktsiyakh v proekte izmenenii i dopolnenii v Grazhdanskii kodeks Rossiiskoi Federatsii // Sbornik po itogam Vserossiiskoi nauchno-prakticheskoi konferentsii «Izmeneniya v Grazhdanskom kodekse Rossiiskoi Federatsii: novelly grazhdanskogo zakonodatel'stva - 2012». M.: Izd-vo «Yurist», 2012. S. 80-81.

12. Cherdantsev A.F. Logiko-yazykovye fenomeny v prave, yuridicheskoi nauke i praktike. Ekaterinburg, 1993. S. $131-132$.

13. Chermyaninov D.V. Tamozhennoe pravo/pod red. D.N. Bakhrakha. M.: Yurait, 2013. - S. 20.

14. Yuridicheskii slovar' [Elektronnyi resurs]. URL: http: //dic.academic.ru/dic.nsf/lower 